\title{
Chemical Composition and Inhibitory Effect of the Essential Oil from Lippia Citriodora Irrigated by Wastewater on the Alkaline Corrosion of Aluminum
}

\author{
F. Bensabah," M. Essahli, A. Lamiri and J. Naja \\ University Hassan 1, Faculty of Science and Techniques, Laboratory of Applied Chemistry and \\ Environment, B.P. 577, Settat, Morocco
}

Received 6 February 2014; accepted 17 November 2014

\begin{abstract}
The objective of this study is the valorization of the essential oil (EO) of Lippia citriodora irrigated by urban wastewater from the city of Settat-Morocco. We have tested it as a corrosion inhibitor of aluminum in $0.1 \mathrm{M} \mathrm{Na}_{2} \mathrm{CO}_{3}$ using polarization method, weight loss, and EIS measurements. The inhibition efficiency of lippia citriodora oil was calculated and compared. We found good agreement between the referred methods. The results obtained revealed that the tested inhibitor reduces differently the kinetic of the corrosion process of aluminum. Its efficiency increases with the concentration and attained $90.33 \%$ at $1800 \mathrm{ppm}$. The effect of temperature on the corrosion behaviour of aluminum in $0.1 \mathrm{M} \mathrm{Na}_{2} \mathrm{CO}_{3}$ was also studied in the range $283 \mathrm{~K}$ and $313 \mathrm{~K}$. The thermodynamic data of activation were determined. The analysis of Lippia citriodora oil, obtained by hydro-distillation, using gas chromatography (GC), showed that the major components are neral $13.85 \%$, geranial $14.06 \%$ and limonene $28.32 \%$.
\end{abstract}

Keywords: Corrosion inhibition; aluminum; Lippia citriodora; Essential oil and Wastewater.

\section{Introduction}

Aluminium is used extensively for the protection, storage and preparation of food and beverages. Aluminium can be rolled into ultra-thin foils which are light, strong and have unique barrier and insulation qualities to preserve food, cosmetics and pharmaceutical products, and protect from ultra-violet light, odours and bacteria. It resists to corrosion and it can be recycled many times with

\footnotetext{
*Corresponding author. E-mail address: bensabah_fati@yahoo.fr
} 
no loss of quality or properties. It is easy to sterilize for food and medical applications. The wide spread application of aluminium is attributed to its excellent properties like corrosion resistance, electrical and thermal conductivity, reflectivity and lightness. It also shows excellent mechanical properties at cryogenic temperatures $[1,2]$.

The corrosion behaviour of aluminium in natural water depends on the nature and chemical composition of the water. Several works have been devoted to study the inhibition of aluminium by inorganic ions [3-12]. However, the majority of the reported works are focussed on chloride containing solutions because of their highly aggressive nature and their widespread occurrence in natural and plant environments [13-15]. A survey of the literature reveals that no systematic work has been devoted to the effect of the addition of metallic cations on the corrosion behaviour of aluminium alloys in media containing chlorides, sulphates or bicarbonates.

Also, we have found that the Mentha Spicata irrigated by wastewater has been a good corrosion inhibitor of aluminum in acidic solution $1 \mathrm{M} \mathrm{HCl} \mathrm{[16].} \mathrm{However,}$ to the best of our knowledge, lippia citriodora irrigated by wastewater has not been used as a corrosion inhibitor for aluminum.

The aim of the present work is to test extracts of Lippia citriodora oil as inhibitors for the alkaline corrosion of aluminum and to discuss their inhibition mechanism.

\section{Experimental part \\ Plant material}

Plantation has been made in May 2009 in experimental plots located in the Faculty of Sciences and Technics of Settat-Morocco (FSTS). Irrigation was done with the urban wastewater purified by lagoons from the city of SettatMorocco. Harvests have been handmade. The quality of the essential oils was also determined using dried leaves of Lippia citriodora.

\section{Water quality irrigation}

The physico-chemical parameters (temperature, $\mathrm{pH}$ and conductivity) were measured in situ by means of a mercury thermometer $\left(1 / 10^{\circ} \mathrm{C}\right)$, a portable $\mathrm{pH}$ meter Lutron ( $\mathrm{pH}-206)$ and a conductivity meter HANNA (HI-8733 with a margin of error of 2\%). In the laboratory, the waters were analyzed for major ions $\left(\mathrm{Ca}^{2+}, \mathrm{Mg}^{2+}, \mathrm{NH}_{4}^{+}, \mathrm{Cl}^{-}, \mathrm{SO}_{4}^{-}\right.$and $\left.\mathrm{HCO}_{3}{ }^{-}\right)$and the nutritive salts. Chlorides and alkalinity were determined by titration (Appendix Table; Rodier 1996). The analysis of metallic trace elements was carried out by the ICP technique.

\section{Extraction of lippia citriodora essential oil}

The distillation apparatus consisted of a heating cap, a 1.5 L extraction flask, a cooling system and a receiver for hydrodistillate. Thirty grams of dried plant leaves and $800 \mathrm{~mL}$ of water were used, and the distillation was carried out for 3 hours after the mixture reached boiling at $100{ }^{\circ} \mathrm{C}$. Hydrodistillation repetitions were done at least in duplicate depending on the availability of the spearmint leaves. The essential oil obtained was dried under anhydrous 
sodium sulfate and stored at $4{ }^{\circ} \mathrm{C}$ in the dark. After extraction, essential oil has been divided into two parts: one was used for chemical analysis, while the second was used to study the inhibitory tests.

\section{Gas chromatography-mass spectrometry}

The essential oil was characterized using a gas chromatograph Trace GC Ultra equipped with an auto injector (Triplus) directly interfaced with a mass spectrophotometer with a flame ionization detector (Pdains Q). Capillary column was DB-5 (5\% of diphenyl and 95\% of dimethylpolysiloxane), $30 \mathrm{~m}$ in length, and $0.25 \mathrm{~mm}$ thickness. Separation conditions were: $25^{\circ} \mathrm{C}$ for $2 \mathrm{~min}, 25-200{ }^{\circ} \mathrm{C}$ at $4{ }^{\circ} \mathrm{C} / \mathrm{min}$, and $180-300{ }^{\circ} \mathrm{C}$ at $40{ }^{\circ} \mathrm{C} / \mathrm{min}$. Temperature of the injector was 220 ${ }^{\circ} \mathrm{C}$. The volume injected was $0.1 \mu \mathrm{L}$. The carrier gas was helium with a flow rate of $1.4 \mathrm{~mL} \cdot \mathrm{min}^{-1}$. The oil constituents were identified by comparison of their retention indices and their mass spectra with those of authentic samples. Quantitative analysis (in percent) was performed by peak area measurement.

\section{Weight loss tests}

Distilled water and $\mathrm{Na}_{2} \mathrm{CO}_{3}$ were used for preparing aggressive solutions. Prior to all measurements, the aluminum samples were polished with different emery papers up to 1200 grade, washed thoroughly with distilled water, degreased with acetone and drying at room temperature. The solution volume was $30 \mathrm{~mL}$. The used aluminum specimens had a rectangular form, with a surface area of $7.5 \mathrm{~cm}^{2}$. The immersion time for the weight loss was $1 \mathrm{~h}$ at $25^{\circ} \mathrm{C}$. After the corrosion test, the specimen of aluminum was carefully washed in distilled water, dried and then weighed.

The rinse removed loose segments of the film of the corroded samples. Duplicate experiments were performed in each case and the mean value of the weight loss was reported. Weight loss allowed us to calculate the mean corrosion rate as expressed in $\mathrm{mg} \cdot \mathrm{cm}^{-2} \cdot \mathrm{h}^{-1}$.

\section{$R p$, polarisation and EIS measurements}

Electrochemical measurements were carried out in a conventional three-electrode electrolysis cylindrical Pyrex glass cell. The working electrode (WE) in the form of disc cut from aluminum has a geometric area of $1 \mathrm{~cm}^{2}$. A saturated calomel electrode (SCE) and a disc platinum electrode were used respectively as reference and auxiliary electrodes. The temperature was thermostatically controlled at $25{ }^{\circ} \mathrm{C}$. The WE was abraded with different emery papers up to 1200 grade, degreased with acetone, and rinsed with distilled water before use.

Running on a compatible computer, the Voltab Master4 Software communicates with Instruments potentiostat-galvanostat model PGZ100 at a scan rate of 20 $\mathrm{mV} / \mathrm{sec}$. Before recording the polarization curves, the working electrode is maintained for $10 \mathrm{~min}$ to Ecorr. The resulting current is plotted as a function of the potential. Polarization resistance $(\mathrm{Rp})$ values were obtained from the current potential plot. The scan rate was $10 \mathrm{mV} / \mathrm{sec}$. The electrochemical impedance spectroscopy (EIS) was performed with an electrochemical system which includes a potentiostat Volta PGZ 100 connected with the computer, being the working electrode in alunimium with a circular form of $1 \mathrm{~cm}^{2}$. 
Frequencies between $100 \mathrm{kHz}$ and $10 \mathrm{mHz}$ were superimposed on the corrosion potential. The impedance diagrams are given in the Nyquist representation. Values of Rt and Cdl were obtained from Nyquist plots.

\section{Results and discussion}

\section{Physicochemical analysis of irrigation water}

Throughout the experiment, the chemical composition of this water source of irrigation has been determined and is detailed in Table 1. The gravity irrigation of the planting is done 1 day / 3 sources, and water was analyzed at each irrigation. Wastewater physico-chemical analyzes showed that the chemical oxygen demand is high and the concentration of $\mathrm{Cl}^{-}$ion exceeds the standard because urban water is responsible by chloride ions. Other physico-chemical parameters meet the standards as metallic trace elements.

Table 1. Characterization of wastewater purified by lagoons used for irrigation in the study.

\begin{tabular}{|c|c|c|}
\hline \multirow{2}{*}{ Parameter } & \multicolumn{2}{|c|}{ Wastewater purified } \\
\hline & Average value & Norm $^{(*)}$ \\
\hline pH & 7.63 & $6.5-8.4$ \\
\hline Temperature $/{ }^{\circ} \mathrm{C}$ & 29.36 & 35 \\
\hline Conductivity at $20{ }^{\circ} \mathrm{C} \mu \mathrm{s} / \mathrm{cm}$ & 1313.64 & 1200 \\
\hline Biological Oxygen Demand $\mathrm{mgO}_{2} / \mathrm{L}$ & 27 & - \\
\hline Chemical Oxygen Demand $\mathrm{mgO}_{2} / \mathrm{L}$ & 656.36 & - \\
\hline $\mathrm{NH}_{4}{ }^{+} \mathrm{mg} / \mathrm{L}$ & 11.25 & - \\
\hline $\mathrm{Cl}^{-} \mathrm{mg} / \mathrm{L}$ & 850.7 & 350 \\
\hline $\mathrm{Ca}^{2+} \mathrm{mg} / \mathrm{L}$ & 97.94 & - \\
\hline $\mathrm{Mg}^{2+} \mathrm{mg} / \mathrm{L}$ & 53.63 & - \\
\hline $\mathrm{HCO}_{3}^{-} \mathrm{mg} / \mathrm{L}$ & 67.65 & 512 \\
\hline $\mathrm{N}-\mathrm{NO}_{2}^{-} \mathrm{mg} / \mathrm{L}$ & 0.09 & 30 \\
\hline $\mathrm{PO}_{4}{ }^{3--} \mathrm{mg} / \mathrm{L}$ & 3.27 & - \\
\hline $\mathrm{SO}_{4}{ }^{2-} \mathrm{mg} / \mathrm{L}$ & 124.00 & 350 \\
\hline Suspended matter mg/L & 130.4 & 200 \\
\hline $\mathrm{Cd} \mathrm{mg} / \mathrm{L}$ & $\leq 0.002$ & 0.01 \\
\hline $\mathrm{Cr}$ mg/L & 0.004 & 1 \\
\hline Cu mg/L & 0.0075 & 0.2 \\
\hline Ni mg/L & 0.012 & 2 \\
\hline Zn mg/L & 0.089 & 2 \\
\hline Hg mg/L & $\leq 0.01$ & 0.001 \\
\hline
\end{tabular}

(*): Standards of water quality for irrigation S.E.E.E-2007- Morocco (Secretariat of the Ministry of Energy, Mines, Water and Environment).

\section{Chemical composition of Lippia citriodora essential oil}

The GC-MS analyzes of Lippia citriodora essential oil irrigated by urban wastewater purified by lagoons from the city of Settat-Morocco are presented in the Table 2.

Lippia citriodora of Morocco still contains as main composition: limonene $(28,32 \%)$, neral $(13,85 \%)$ and geranial $(14,06 \%)$ (Fig. 1). However, our results did not show the presence of p-cymene, camphor and thymol, which have been mentioned in other studies concerning L. citriodora $[17,18]$. 
a

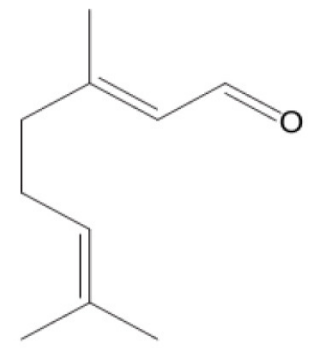

b

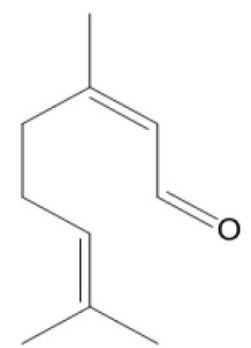

C

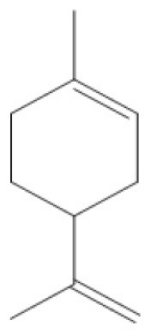

Figure 1. Molecular structures of geranial (a), neral (b) and limonene (c).

Table 2. Chemical composition of Lippia citriodora essential oil irrigated by wastewater from the city of Settat (Morocco) purified by lagoon.

\begin{tabular}{|cc|}
\hline Compounds & A \% \\
\hline a-Pinene & 1.06 \\
Sabinene & 2.42 \\
Limonene & 28.32 \\
Trans-Ocimene & - \\
Nerol & 1.40 \\
Neral & 13.85 \\
Geranial & 14.06 \\
$\boldsymbol{\beta}$-Caryophyllene & 3.35 \\
a-Curcumene & 11.36 \\
Neryl acetate & 2.38 \\
Copaene & 2.38 \\
a-Cadinene & - \\
Spathulenol & 8.29 \\
Caryophyllene oxide & 7.07 \\
Y-Cadinene & 3.86 \\
\hline
\end{tabular}

A: plots irrigated by wastewater from the city of Settat treated lagoon.

\section{Weight loss tests}

The corrosion rate $\left(\mathrm{W}_{\text {corr }}\right)$ of aluminum in $0.1 \mathrm{M} \mathrm{Na}_{2} \mathrm{CO}_{3}$ solution at various contents of the natural oil tested was determined after $1 \mathrm{~h}$ of immersion period at $25{ }^{\circ} \mathrm{C}$. Values of corrosion rates and inhibition efficiencies are given in Table 3. In the case of the weight loss method, the inhibition efficiency (Ew \%) was determined by the following relation:

$$
\mathrm{EW} \%=\frac{\left.W_{\text {corr }}-W_{\text {corr }[\text { [inh }}\right]}{W_{\text {corr }}} \times 100
$$

where $\mathrm{W}_{\text {corr }}$ and $\mathrm{W}_{\text {corr(inh) }}$ are the corrosion rates of aluminum in the absence and presence of the oil, respectively.

The analysis of these results (Table 3 and Fig. 2) shows clearly that the corrosion rate decreases $\left(\mathrm{W}\left(\mathrm{mg} / \mathrm{h} . \mathrm{cm}^{2}\right)\right.$ while the inhibition efficiency $(\mathrm{Ew}(\%))$ increases with increasing inhibitor concentration, reaching a maximum value of $86.74 \%$ at a concentration of $1800 \mathrm{ppm}$. This behaviour can be attributed to the increase of the surface covered $\ominus(\mathrm{Ew} \% / 100)$ and this probably is due to the adsorption of natural compounds on the surface of the metal as the inhibitor concentration 
increases. We can conclude that Lippia oil is a good corrosion inhibitor for aluminum in $0.1 \mathrm{M} \mathrm{Na}_{2} \mathrm{CO}_{3}$ solution.

Table 3. Gravimetric results of aluminum in $0.1 \mathrm{M} \mathrm{Na}_{2} \mathrm{CO}_{3}$ without and with addition of the natural oil at various contents $\left(t=1 \mathrm{~h} . T=25^{\circ} \mathrm{C}\right)$.

\begin{tabular}{|c|c|c|}
\hline Concentration / ppm & $\mathbf{W} \mathbf{~ m g} / \mathbf{c m}^{\mathbf{2}} \mathbf{. h}$ & $\mathbf{E w} / \mathbf{\%}$ \\
\hline Blank & 0.347 & --- \\
\hline $\mathbf{1 2 0 0}$ & 0.177 & 48.99 \\
\hline $\mathbf{1 4 0 0}$ & 0.146 & 57.92 \\
\hline $\mathbf{1 6 0 0}$ & 0.119 & 65.71 \\
\hline $\mathbf{1 8 0 0}$ & 0.046 & 86.74 \\
\hline $\mathbf{2 0 0 0}$ & 0.046 & 86.74 \\
\hline
\end{tabular}

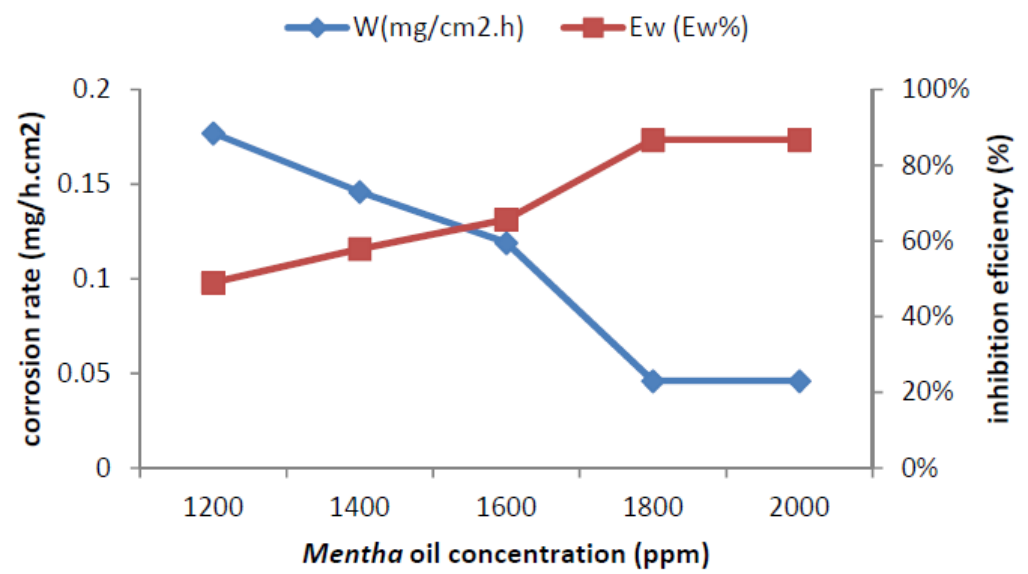

Figure 2. Variation of the corrosion rate and inhibition efficiency of aluminum in $0.1 \mathrm{M}$ $\mathrm{Na}_{2} \mathrm{CO}_{3}$ without and with Lippia citriodora oil.

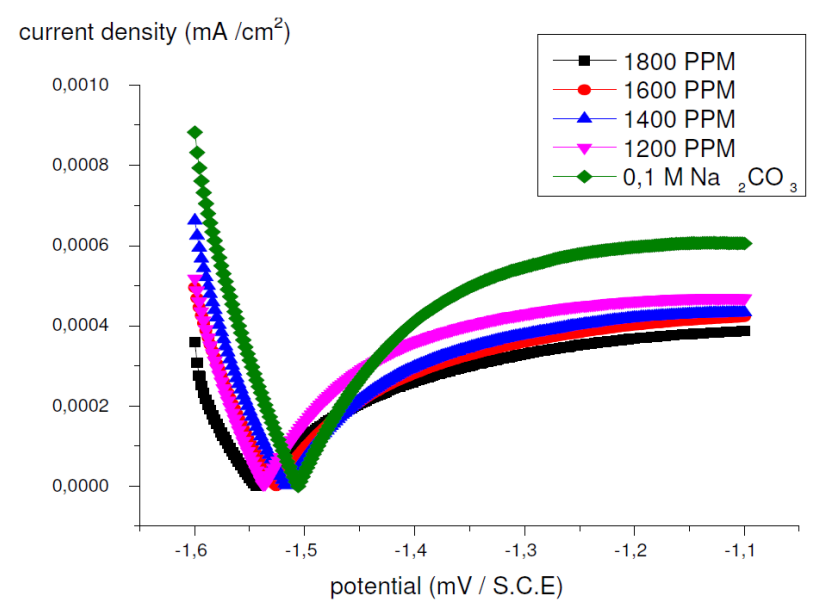

Figure 3. Potentiodynamic polarization curves for aluminum in $0.1 \mathrm{M}$ sodium carbonate in absence and presence of different Lippia citriodora oil concentrations.

\section{Polarisation measurements}

Current-potential characteristics resulting from cathodic and anodic polarisation curves of aluminum in 0.1 molar sodium carbonate at various concentrations of the tested Lippia citriodora oil are evaluated (Fig. 3). 
Table 4 collects the corrosion kinetic parameters such as $E_{\text {corr }}, I_{c o r r}, \beta c$, and $\beta \mathrm{a}$ obtained from potentiodynamic polarization curves for aluminum in $0.1 \mathrm{M}$ $\mathrm{Na}_{2} \mathrm{CO}_{3}$ containing different concentrations of Lippia citriodora oil. In the case of polarization method the following relation determines the inhibition efficiency (EI \%):

$$
\mathrm{EI} \%=\frac{I_{\text {corr }}-I_{\operatorname{corr}(\sinh )}}{I_{\text {corr }}} \times 100
$$

where $I_{\text {corr }}$ and $I_{\text {corr(inh) }}$ are the corrosion current density values without and with the inhibitor, respectively.

Fig. 3 represents the anodic and cathodic polarization curves for aluminum in 0.1 $\mathrm{M}$ sodium carbonate in absence and presence of different concentrations of Lippia citriodora oil. As seen, from this figure the Lippia citriodora oil inhibits both cathodic and anodic parts of the polarization curves.

Table 4 shows the electrochemical polarization parameters, where the corrosion current density, $\left(\mathrm{I}_{\text {corr }}\right)$, was calculated from the intersection of the anodic and cathodic Tafel lines, corrosion potential $\left(\mathrm{E}_{\mathrm{corr}}\right)$, corrosion current density and anodic and cathodic Tafel line slopes $(\beta \mathrm{a}$, and $\beta \mathrm{c})$ for different concentrations of Lippia citriodora oil. The data revealed that, for all concentrations under study, the corrosion current density, that is directly proportional to corrosion rate, decreases with increasing the Lippia citriodora oil concentration.

Table 4. Electrochemical parameters of aluminum at various concentrations of Lippia citriodora oil studied in $1 \mathrm{M} \mathrm{Na}_{2} \mathrm{CO}_{3}$ at $25{ }^{\circ} \mathrm{C}$ and respective corrosion inhibition efficiencies.

\begin{tabular}{|c|c|c|c|c|c|c|}
\hline \multirow{2}{*}{ Inhibitor } & $\begin{array}{c}\text { Concentration } \\
\mathbf{p p m}\end{array}$ & $\begin{array}{c}\mathbf{E}_{\mathbf{c o r r}} \\
\mathbf{m V / S C E}\end{array}$ & $\begin{array}{c}\mathbf{I c o r r} \\
\boldsymbol{\mu} \mathbf{A} / \mathbf{c m}^{2}\end{array}$ & $\begin{array}{c}\boldsymbol{\beta c} \\
\mathbf{m V}\end{array}$ & $\begin{array}{c}\boldsymbol{\beta a} \\
\mathbf{m V}\end{array}$ & $\mathbf{E}_{\mathbf{I}} \%$ \\
\hline \multirow{2}{*}{ Blank } & ---- & -1509.3 & 150.128 & -124.1 & 219.9 & -- \\
\hline \multirow{3}{*}{$\begin{array}{c}\text { Lippia } \\
\text { citriodora } \\
\text { oil }\end{array}$} & 1200 & -1531.8 & 75.785 & -84.7 & 143.6 & 49.52 \\
\cline { 2 - 7 } & 1400 & -1524.2 & 61.762 & -93.3 & 171.7 & 58.86 \\
\cline { 2 - 7 } & 1600 & -1530.8 & 52.735 & -86.9 & 169.4 & 64.87 \\
\cline { 2 - 7 } & 1800 & -1531.4 & 16.514 & -84.4 & 145.1 & 89.00 \\
\hline
\end{tabular}

The values of $E_{\text {corr }}$ shifted slightly to less positive potentials with increasing the concentration of Lippia citriodora oil. The values of the anodic Tafel line slope $(\beta a)$ in presence of the extracts show higher values probably due to the effect of diffusion process.

The data in Table 4 also show that the oil of Lippia citriodora inhibits corrosion of the aluminum in the basic medium and that the efficiency reaches about $89 \%$ at a concentration of $1800 \mathrm{ppm}$ in oil".

\section{Electrochemical impedance spectroscopy (EIS)}

The corrosion behaviour of aluminum in 0.1 molar sodium carbonate, in the absence and presence of Lippia citriodora oil, is also investigated by electrochemical impedance spectroscopy (EIS) at $25{ }^{\circ} \mathrm{C}$. The charge-transfer 
resistance $(\mathrm{Rt})$ values are calculated from the difference in impedance at lower and higher frequencies, as suggested by Tsuru et al. [19]. The double layer capacitance $\left(\mathrm{C}_{\mathrm{dl}}\right)$ and the frequency at which the imaginary component of the impedance is maximal (-Zmax) are found as represented in equation:

$$
\mathrm{C}_{\mathrm{dl}}=\frac{1}{R \cdot T}, \text { where } \mathrm{w}=2 \pi \mathrm{f}_{\max }
$$

Impedance diagrams are obtained for the frequency range $100 \mathrm{KHz}-10 \mathrm{mHz}$ for aluminum in 0.1 molar sodium carbonate in the presence and absence of Lippia citriodora oil. Nyquist plots for aluminum in $1 \mathrm{M} \mathrm{Na}_{2} \mathrm{CO}_{3}$ and in $1800 \mathrm{ppm}$ concentration of Lippia citriodora oil are presented in Fig. 4.

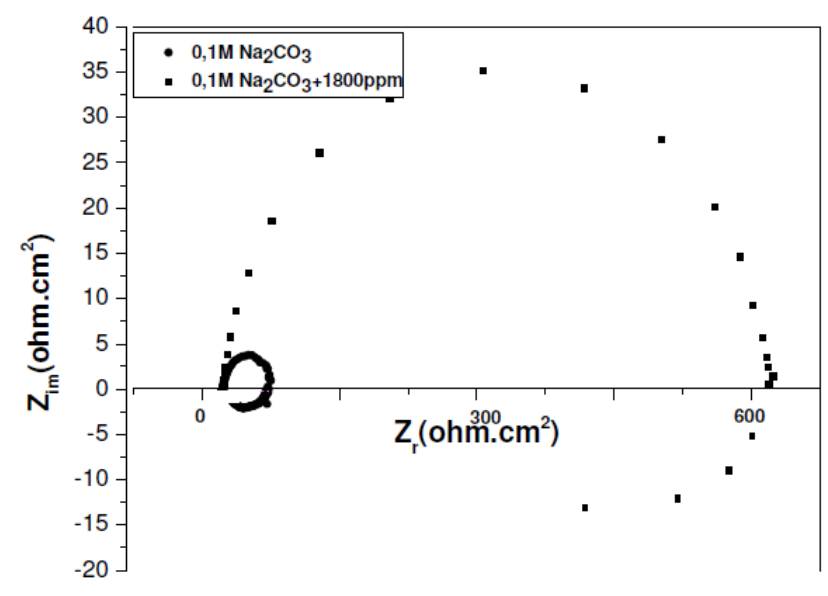

Figure 4. Nyquist plots of aluminum with and without Lippia citriodora oil.

The Nyquist impedance plots explain that the impedance response consists of a capacitive semicircle followed by an inductive loop, indicating that the dissolution process occurs under activation control. The inductive loop is generally attributed to the adsorption of the species resulting from metal dissolution and hydrogen adsorption [20]. The impedance spectra for different Nyquist plots were analyzed by fitting the experimental data to a simple equivalent circuit model (Fig. 5) which includes the solution resistance, Rs, and the double layer capacitance, $\mathrm{C}_{\mathrm{dl}}$, which is placed in parallel to charge the transfer resistance element, Rt. The Rt value is a measure of electron transfer across the surface and is inversely proportional to the corrosion rate.

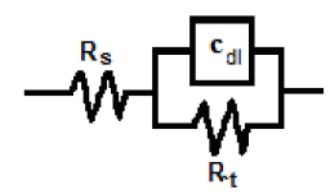

Figure 5. The equivalent circuit model.

Table 5 presents values of charge transfer resistance, Rt, double-layer capacitance, $\mathrm{C}_{\mathrm{dl}}$, and $\mathrm{f}_{\max }$ derived from Nyquist plots and inhibition efficiency; the inhibition efficiency gotten from the charge-transfer resistance is calculated by the following relation: 


$$
\text { ERt } \%=\frac{R_{t}^{\prime}-R_{t}}{R_{t}^{\prime}} \times 100
$$

Rt and R't are the charge-transfer resistance values without and with inhibitor, respectively.

Table 5. Characteristic parameters evaluated from the impedance diagram for aluminum without and with Lippia citriodora oil.

\begin{tabular}{|c|c|c|c|c|}
\hline Inhibitor & $\mathbf{R t}$ Ohm.cm & $\mathbf{f}_{\mathbf{m a x}} / \mathbf{H z}$ & $\begin{array}{c}\mathbf{C}_{\mathbf{d l}} \\
\boldsymbol{\mu} \mathbf{F} / \mathbf{c m}^{2}\end{array}$ & $\mathbf{E}_{\mathbf{R t}} \%$ \\
\hline $\mathrm{Na}_{2} \mathrm{CO}_{3} 0.1 \mathrm{M}$ & 58.5 & 102.27 & 26.6 & ------ \\
\hline $\begin{array}{c}\text { Lippia citriodora oil } \\
1800 \text { ppm }\end{array}$ & 605.2 & 12.83 & 20.5 & 90.33 \\
\hline
\end{tabular}

Increasing Rt values with the concentration of the oil suggests decrease of the corrosion rate, since the $\mathrm{Rt}$ value is a measure of electron transfer across the surface, and inversely proportional to the corrosion rate. The decrease in the $\mathrm{C}_{\mathrm{dl}}$ values could be attributed to the adsorption of the chemical constituents of the extracts at the metal surface [21].

The tabulated data also indicate that Lippia citriodora oil has considerable effect for the corrosion of aluminum in $0.1 \mathrm{M} \mathrm{Na}_{2} \mathrm{CO}_{3}$ solution.

As seen, the inhibition efficiency of the Lippia citriodora oil is arranged according to Table 6 . The data show that there is a considerable agreement between the data obtained from the three techniques: weight loss, polarization, and EIS.

Table 6. Comparison between \%P of Lippia citriodora oil (1800 ppm) obtained from weight loss, polarization and impedance techniques.

\begin{tabular}{|c|c|c|c|}
\cline { 2 - 4 } \multicolumn{1}{c|}{} & weight loss & polarization & impedance technique \\
\hline Lippia citriodora oil & 86.74 & 89 & 90.33 \\
\hline
\end{tabular}

\section{Mechanism of corrosion of aluminum in alkaline solutions}

a) Anodic reaction (dissolution of aluminum):

The anodic potentiodynamic polarization curves of aluminum in $0.1 \mathrm{M} \mathrm{Na}_{2} \mathrm{CO}_{3}$ in absence or in presence of the Lippia citriodora oil show a limiting current, indicating that the dissolution of aluminum is controlled by the diffusion of $\mathrm{Al}(\mathrm{OH})_{4}{ }^{-}$or $\mathrm{AlO}_{2}{ }^{-}$from the surface of the metal to the bulk of solution. Then the anodic dissolution of aluminum can be represented as:

or

$$
\mathrm{Al}+4 \mathrm{OH}^{-} \rightleftharpoons \mathrm{Al}(\mathrm{OH})^{-}+3 \mathrm{e}^{-}
$$

$$
\mathrm{Al}+4 \mathrm{OH}^{-} \rightleftharpoons \mathrm{AlO}_{2}^{-}+2 \mathrm{H}_{2} \mathrm{O}+3 \mathrm{e}^{-}
$$




\section{b) Cathodic reaction (reduction of water):}

The cathodic polarization curve of aluminum in $0.1 \mathrm{M} \mathrm{Na}_{2} \mathrm{CO}_{3}$ in absence or in presence of the Lippia citriodora oil shows Tafel behavior, indicating that the reduction process is controlled by charge transfer and can be represented by:

$$
\mathrm{H}_{2} \mathrm{O}+\mathrm{e}^{-} \rightleftharpoons 1 / 2 \mathrm{H}_{2}+\mathrm{OH}^{-}
$$

\section{c) Overall corrosion reaction:}

The impedance spectroscopy data of aluminum $0.1 \mathrm{M} \mathrm{Na}_{2} \mathrm{CO}_{3}$ in absence or in presence of the Lippia citriodora oil measured at the equilibrium potential indicated that the corrosion of aluminum is controlled by charge transfer. This means that the reduction of water at cathodic areas is the slow step of corrosion of aluminum. The equation corresponding to the overall reaction of corrosion of aluminum in $0.1 \mathrm{M} \mathrm{Na}_{2} \mathrm{CO}_{3}$ solution can be obtained if eq. (7) is multiplied by 3 and then added to eq. (9):

$$
\begin{aligned}
& 3 \mathrm{H}_{2} \mathrm{O}+3 \mathrm{e}^{-} \rightarrow 3 / 2 \mathrm{H}_{2}+3 \mathrm{OH}^{-} \\
& \mathrm{Al}+4 \mathrm{OH}^{-} \rightleftharpoons \mathrm{AlO}_{2}^{-}+2 \mathrm{H}_{2} \mathrm{O}+3 \mathrm{e}^{-} \\
& \mathrm{Al}+\mathrm{H}_{2} \mathrm{O}+\mathrm{OH}^{-} \rightleftharpoons 3 / 2 \mathrm{H}_{2}+\mathrm{AlO}_{2}^{-}
\end{aligned}
$$

\begin{tabular}{|c|c|c|c|}
\hline Temperature $/{ }^{\circ} \mathbf{C}$ & W $\mathrm{mg} / \mathrm{cm}^{2} . \mathrm{h}$ & $\mathrm{W}^{\prime} \mathbf{m g} / \mathrm{cm}^{2} \cdot \mathrm{h}$ & $\mathrm{E} \%$ \\
\hline 10 & 0.231 & 0.032 & 86.15 \\
\hline 20 & 0.304 & 0.034 & 88.81 \\
\hline 30 & 1.267 & 0.186 & 85.32 \\
\hline 40 & 1.937 & 0.347 & 82.08 \\
\hline
\end{tabular}

Table 7. Effect of temperature on the aluminum corrosion in the presence and absence of 1800 ppm oil for 1 hour.

\section{Effect of temperature}

The effect of temperature on the corrosion behaviour of aluminum in $0.1 \mathrm{M}$ $\mathrm{Na}_{2} \mathrm{CO}_{3}$ containing the inhibitor at a concentration of $1800 \mathrm{ppm}$ is studied in the temperature range $10-40{ }^{\circ} \mathrm{C}$ using weight loss measurements. Table 7 regroups the corresponding obtained results.

It is obvious that the corrosion rate increases both in the uninhibited and inhibited alkaline solution with the rise of temperature. The presence of the inhibitor leads to the decrease of the corrosion rate, E\%, which decreases with the increase of temperature.

The following relation can determine the apparent activation energy:

$$
\mathrm{W}_{\text {corr }}=\mathrm{k}_{\exp }\left(-\mathrm{E}_{\mathrm{a}} / \mathrm{RT}\right) \text { and } \mathrm{W}^{\prime}{ }_{\text {corr }}=\mathrm{k}_{\exp }^{\prime}\left(-\mathrm{E}_{\mathrm{a}}^{\prime} / \mathrm{RT}\right)
$$

$\mathrm{W}^{\prime}$ corr and $\mathrm{W}_{\text {corr }}$ are the corrosion rates of aluminum with and without inhibitor, respectively. $\mathrm{E}_{\mathrm{a}}$ and $\mathrm{E}_{\mathrm{a}}$ are the apparent activation energies in the presence and absence of the inhibitor, respectively. 


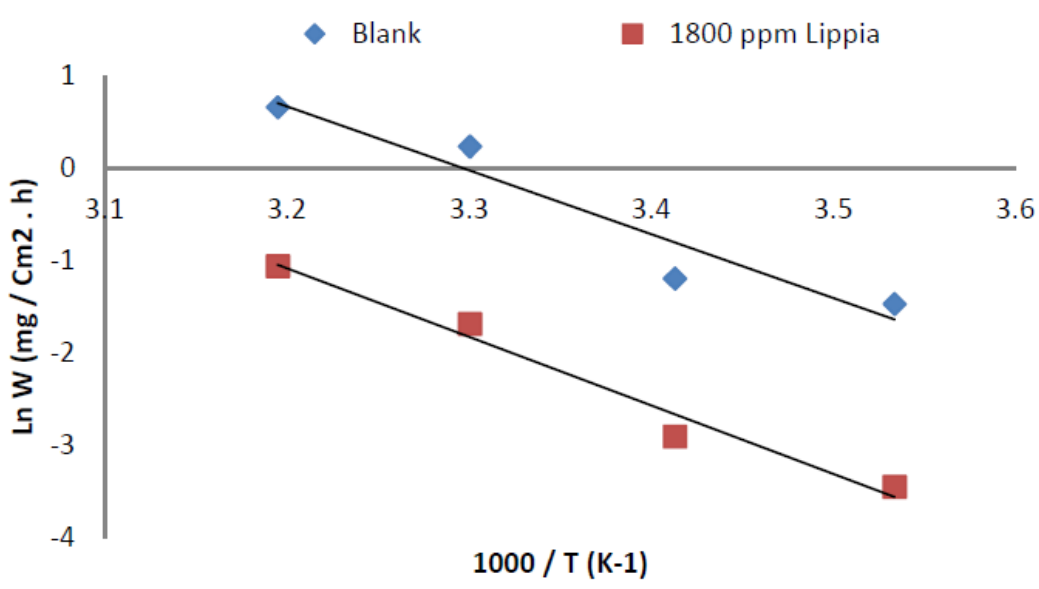

Figure 6. Arrhenius plots of aluminum in uninhibited and inhibited solutions.

Arrhenius plots for the corrosion rates of aluminum are shown in Fig. 6. The calculated values of activation energies from the slopes are 48.55 and 112.32 $\mathrm{kJ} / \mathrm{mol}$ for blank and with the addition of $1800 \mathrm{ppm}$ of Lippia citriodora oil, respectively.

It is found that the activation energy increases in the presence of the inhibitor. Furthermore, the decrease of $\mathrm{E} \%$ is explained due to the physisorption of the inhibitor molecule on the steel surface [22]. The lower value of $E_{a}$ of the corrosion process in the inhibitor's presence when compared to that in its absence is attributed to its chemisorption [23].

\section{Adsorption isotherm}

The dependence of the fraction of the surface covered $\ominus$ obtained by the ratio E\%/100 as a function of the oil concentration (C) was graphically fitted for Langmuir, Temkin and Frumkin adsorption isotherms. Fig. 7 shows the dependence of $\mathrm{C} / \Theta$ as a function of the oil concentration. The curve obtained clearly shows that the data fit well with Langmuir adsorption isotherm and this was found to be the best description of the adsorption behaviour of the studied inhibitor, which obeys:

$$
\frac{c}{\ominus}=\frac{1}{K a d s}+C
$$

$\mathrm{C}$ is the inhibitor concentration; $\Theta$ is the fraction of the surface covered, Kads is the adsorption coefficient.

The literature shows that the adsorption of heterocyclic compounds occurs with the aromatic rings mostly perpendicular with respect to the metal surface at low concentration, but at elevated inhibitor concentration the molecules are reoriented to the parallel mode [23]. Besides, the adsorption phenomenon may be made by carvone as the principal constituent of the essential oil of Lippia citriodora. But as the natural oil contains so many components, the inhibitory action may also be due to synergistic intermolecular of the active molecules of this oil [24]. 


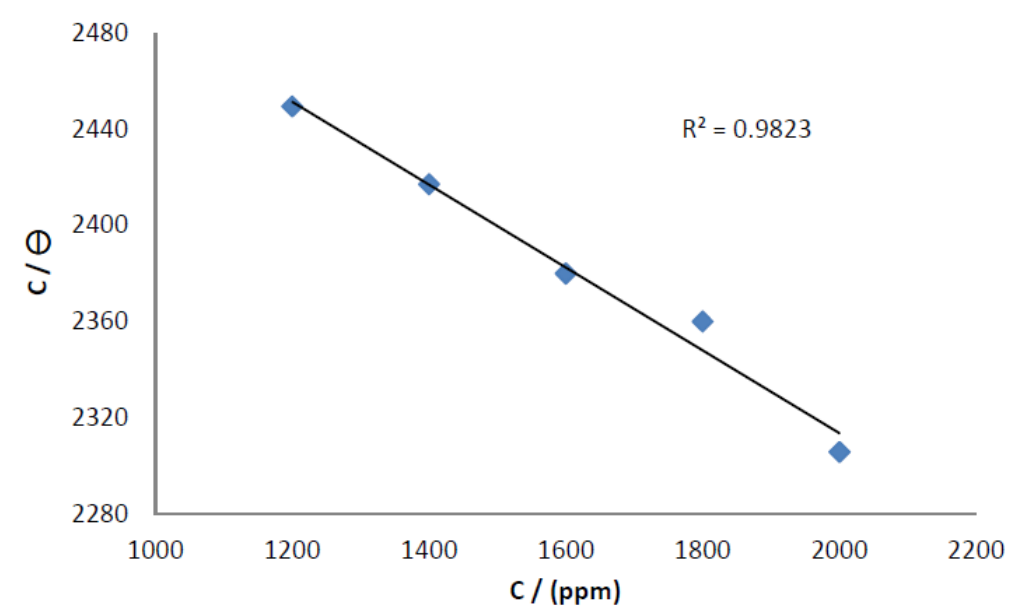

Figure 7. Langmuir adsorption isotherm of Lippia citriodora oil on the aluminum surface.

\section{Conclusions}

From the overall experimental results the following conclusions can be deduced:

- chemical analysis showed limonene, neral and geranial as major components of Lippia citriodora essential oil;

- Lippia citriodora oil acts as good inhibitor for the corrosion of aluminum in 0.1 $\mathrm{Na}_{2} \mathrm{CO}_{3}$ medium;

- the inhibition efficiency of Lippia citriodora oil increases with concentration to attain $90.33 \%$ at $1800 \mathrm{ppm}$;

- the inhibition efficiency of Lippia citriodora oil decreases with the rise of temperature;

- the Lippia citriodora essential oil acts on aluminum surface as a mixed inhibitor through a physisorption mechanism.

\section{References}

1. Hunter MS, Fowle P. J Electrochem Soc. 1956;103:482.

2. Fontana MG, Greene ND. Corrosion Engineering. McGraw-Hill; 1978.

3. Bazzi L, Kertit S, Hamdani M. Corrosion. 1995;51:811.

4. Bazzi L, Kertit S, Hamdani M. J Chim Phys. 1995;92:1612.

5. Bazzi L, Kertit S, Hamdani M. J Chim Phys. 1997;94:93.

6. Bazzi L, Kertit S, Hamdani M. Bull Electrochem. 1998;14:34.

7. Mosheir WC, Davis GD, Aheran K. Corros Sci. 1987;27:785.

8. Salghi R, Bazzi L, Hammouti B, et al. Ann Chim Mater. 2000;25:593.

9. Bazzi L, Kertit S, Hamdani M. Rev Metal Sci Gen Mater. 1994;12:1835.

10. Salghi R, Bazzi L, Zaafrani M. Acta Chim Slov. 2003;50:491.

11. Bazzi L, Salghi R, Bouchtart A, et al. Rev Metal Sci Gen Mater. 2002;2:189.

12. Bazzi L, Salghi R, El Alami Z, et al. Can J Chem. 2002;80:106.

13. Nguyen TH, Foley RT. J Electrochem Soc. 1979;126:1855.

14. Berzins A, Lowson RT, Mirams KJ. Aust J Chem. 1977;30:1891. 
15. Lowson RT. Aust J Chem. 1978;31:943.

16. Bensabah F, Houbairi S, Essahli M, et al. Port Electrochim Acta. 2013;31:195

17. Kim N-S, Lee D-S. J Sep Sci. 2004;27:96.

18. Zygadlo JA, Lamarque AL, Maestri DM, et al. J Essent Oil Res. 1994;6:407.

19. Tsuru T, Haruyama S, Gijutsu B. J Jpn Soc Corros Eng. 1978;27:573.

20. Dehri Y, Erbil M. Corros Sci. 2000;42:969.

21. Aramaki K, Hagiwara M, Nishihara H. Corros Sci. 1987;5:487.

22. Dahmani M, Et-Touhami A, Al-Deyab SS, et al. Int J Electrochem Sci. 2010;5:1060.

23. Zarrouk A, Warad I, Hammouti B, et al. Int J Electrochem Sci. 2010;5:1516.

24. Bockris JOM, Young B. J Electrochem Soc. 1999;138:2237. 